Check for updates

Cite this: RSC Adv., 2019, 9, 27652

Received 25th June 2019

Accepted 21st August 2019

DOI: $10.1039 / c 9 r a 04790 e$

rsc.li/rsc-advances

\title{
A turn-on fluorescent probe with a dansyl fluorophore for hydrogen sulfide sensing $†$
}

\begin{abstract}
Yehan Yan, (D) $\dot{t}^{\mathrm{a}}$ Lijuan Chen, $\stackrel{+}{\mathrm{a}}^{\mathrm{a}}$ Renyong Liu, ${ }^{\mathrm{a}}$ Yu Zheng ${ }^{\mathrm{a}}$ and Suhua Wang (iD) *b
Hydrogen sulfide $\left(\mathrm{H}_{2} \mathrm{~S}\right)$ is a biologically relevant molecule that has been newly identified as a gasotransmitter and is also a toxic gaseous pollutant. In this study, we report on a metal complex fluorescent probe to achieve the sensitive detection of $\mathrm{H}_{2} \mathrm{~S}$ in a fluorescent "turn-on" mode. The probe bears a dansyl fluorophore with multidentate ligands for coordination with copper ions. The fluorescent "turn-on" mode is facilitated by the strong bonding between $\mathrm{H}_{2} \mathrm{~S}$ and the $\mathrm{Cu}(I)$ ions to form insoluble copper sulfide, which leads to the release of a strongly fluorescent product. The $\mathrm{H}_{2} \mathrm{~S}$ limit of detection (LOD) for the proposed probe is estimated to be $11 \mathrm{nM}$ in the aqueous solution, and the utilization of the probe is demonstrated for detecting $\mathrm{H}_{2} \mathrm{~S}$ in actual lake and mineral water samples with good reproducibility. Furthermore, we designed detector vials and presented their successful application for the visual detection of gaseous $\mathrm{H}_{2} \mathrm{~S}$.
\end{abstract}

\section{Introduction}

Hydrogen sulfide $\left(\mathrm{H}_{2} \mathrm{~S}\right)$ is a highly toxic air pollutant that is widely generated from industrial production processes, involving sulfuric acid, sulfur, dyes, and cosmetics, as well as the microbial degradation processes by which anaerobic bacteria reduce inorganic sulfates and organic sulfides. ${ }^{1}$ Prolonged exposure to $\mathrm{H}_{2} \mathrm{~S}$ may lead to respiratory paralysis, olfactory fatigue, vagueness of consciousness, and even permanent cerebral injury. ${ }^{2,3}$ In addition, $\mathrm{H}_{2} \mathrm{~S}$ is a newly identified endogenous gaseous transmitter molecule like NO and $\mathrm{CO}$, which has been associated with the regulation of cardiovascular, vasodilation, central nervous, respiratory, and immune systems. ${ }^{4-10}$ The level of $\mathrm{H}_{2} \mathrm{~S}$ in humans has been documented to be between 10 and $100 \mu \mathrm{M}$, and an abnormal concentration of $\mathrm{H}_{2} \mathrm{~S}$ has been related with Down syndrome, diabetes, Alzheimer's disease, and arterial and pulmonary hypertension. ${ }^{\mathbf{1 1 - 1 3}}$ Therefore, analytical approaches capable of conducting selective and sensitive $\mathrm{H}_{2} \mathrm{~S}$ detection in complicated environmental and biological systems are essential.

Current techniques employed for $\mathrm{H}_{2} \mathrm{~S}$ analysis include chemical titration, ${ }^{\mathbf{1 4}, \mathbf{1 5}}$ colorimetry, ${ }^{\mathbf{1 6}}$ electrochemical assay, ${ }^{\mathbf{1 7}}$ gas chromatography, ${ }^{18}$ and inductively coupled plasma atomic emission spectroscopy (ICP-AES). ${ }^{19}$ Compared to these methods, fluorescence analysis has proven to be a promising option because of its high sensitivity, high temporal and spatial

${ }^{a}$ West Anhui University, Luan, Anhui 237012, China

${ }^{b}$ School of Environmental Science and Engineering, North China Electric Power University, Beijing 102206, China. E-mail: wangsuhua@ncepu.edu.cn

$\dagger$ Electronic supplementary information (ESI) available. See DOI: 10.1039/c9ra04790e

\$ Yehan Yan and Lijuan Chen contributed equally to this work. detection resolutions, and the ability for conducting in situ monitoring of reactive and transient target analytes. ${ }^{\mathbf{2 0 - 2 7}}$ Generally, the fluorescence probes for $\mathrm{H}_{2} \mathrm{~S}$ mainly based on reduction reactions, ${ }^{28-32}$ nucleophilic addition reactions, ${ }^{33-35}$ and thiolysis reactions. ${ }^{36-38}$ In addition, metal displacement approach utilizes the strong affinity of metal ions with sulfides ions to rapidly attain reaction equilibrium, and achieve the realtime detection of $\mathrm{H}_{2} \mathrm{~S}^{39,40}$

Based on metal displacement approach of copper metal complexes, some colorimetric or fluorescent sensors for $\mathrm{H}_{2} \mathrm{~S}$ have been emerging in recent years, owning to the low solubility product of $\mathrm{CuS}\left(K_{\mathrm{sp}}=6.3 \times 10^{-36}\right)$. For example, Li et al. synthesized a Cu-complex probe (BODIPY-DPA-Cu) by attaching di-(2-picolyl)amine (DPA) and BODIPY dye, in the presence of $\mathrm{H}_{2} \mathrm{~S}$, the fluorescence at $546 \mathrm{~nm}$ enhanced 19-fold in the PBS buffer (10 mM, pH 7.4). It showed a high sensitivity and selectivity for sulfide. ${ }^{41} \mathrm{Kim} \mathrm{J}$. Y. and co-workers developed a $\mathrm{Cu}$ cyclen-dansyl (Cu-CD) probe for the quantification of $\mathrm{H}_{2} \mathrm{~S}$ in PBS buffer containing 10\% DMSO with good selectivity among competitive anions. ${ }^{42}$ Kaushik and co-workers designed a probe for selective detection of $\mathrm{H}_{2} \mathrm{~S}$ by copper complex embedded in vesicles, different from the MDA mechanism, in which both metal and indicator get displaced upon binding of $\mathrm{H}_{2} \mathrm{~S}$ with metal center. ${ }^{43}$ Other relevant probes for $\mathrm{H}_{2} \mathrm{~S}$ detection based copper metal complexes are listed in Table $\mathrm{S} 1 . \dagger^{\mathbf{4 4 - 5 1}}$

The present work capitalizes on this property by combining a dansyl fluorophore with a $\mathrm{Cu}(\mathrm{II})$ metal complex to design a displacement-reaction-based probe for $\mathrm{H}_{2} \mathrm{~S}$ detection in a fluorescent "turn-on" mode. The fluorescent metal complex probe includes a multidentate ligand that can coordinate with $\mathrm{Cu}^{2+}$ ions to produce a stable dansyl fluorophore Cu-complex (DNS-Cu). The DNS-Cu complex exhibits a very weak 
background fluorescence because the empty d orbital of paramagnetic $\mathrm{Cu}$ (II) can accept the excited state electrons in the DNS fluorophore, and hence, block the process of ligand fluorescence generation. In addition, $\mathrm{H}_{2} \mathrm{~S}$ strongly binds with the $\mathrm{Cu}^{2+}$ ions to form CuS and releases a free fluorescent DNS fluorophore, resulting in a greatly enhanced probe fluorescence. The $\mathrm{H}_{2} \mathrm{~S}$ limit of detection (LOD) for the proposed probe (DNS$\mathrm{Cu}$ ) is determined to be $11 \mathrm{nM}$, and the probe demonstrates good $\mathrm{H}_{2} \mathrm{~S}$ selectivity, reproducibility, and anti-interference performance. In addition, the probe was used to develop detector vials for visualizing gaseous $\mathrm{H}_{2} \mathrm{~S}$, which demonstrates the applicability of the proposed fluorescent probe for sensing $\mathrm{H}_{2} \mathrm{~S}$ gas in the environment.

\section{Experimental}

\subsection{Materials}

All of reagents were received from commercial suppliers. Sodium sulfide $\left(\mathrm{Na}_{2} \mathrm{~S}\right)$, sodium nitrate $\left(\mathrm{NaNO}_{3}\right)$, sodium sulfate $\left(\mathrm{Na}_{2} \mathrm{SO}_{4}\right)$, sodium thiocyanate (NaSCN), sodium thiosulfate $\left(\mathrm{Na}_{2} \mathrm{~S}_{2} \mathrm{O}_{3}\right)$, sodium fluoride $(\mathrm{NaF})$, sodium chloride $(\mathrm{NaCl})$, sodium nitrate $\left(\mathrm{NaNO}_{3}\right)$, sodium nitrite $\left(\mathrm{NaNO}_{2}\right)$, sodium bromide $(\mathrm{NaBr})$, potassium iodide $(\mathrm{KI})$, sodium sulfite $\left(\mathrm{Na}_{2} \mathrm{SO}_{3}\right)$, sodium hypochlorite $(\mathrm{NaClO})$, trisodium phosphate $\left(\mathrm{Na}_{3} \mathrm{PO}_{4}\right)$, copper(II) chloride dihydrate $\left(\mathrm{CuCl}_{2} \cdot 2 \mathrm{H}_{2} \mathrm{O}\right)$, reduced glutathione (GSH), L-cysteine (L-Cys), $N, N$-dimethyl formamide, ethyl acetate (EA), petroleum ether (PE), dichloromethane, anhydrous potassium carbonate, 5-dimethylamino-1-naphthalenesulfonyl chloride, triethylamine, methanol and 2-chloroethylamine hydrochloride. Adenosine 5'-diphosphate disodium salt (ADP), adenosine $5^{\prime}$-triphosphate disodium salt (ATP), adenosine $5^{\prime}$ monophosphate (AMP), pyrophosphoric acid (PPi), the ultrapure water $(18.2 \mathrm{M} \Omega \mathrm{cm})$ was used throughout the experiments.

\subsection{Instrumentation}

The fluorescence spectra were obtained on a PerkinElmer LS-55 luminescence spectrometer. Mass spectra were recorded on a Thermo Proteome X-LTQ MS. ${ }^{1} \mathrm{H}$-NMR spectrum was acquired on a Brucker Avance $400 \mathrm{MHz}$, using $\mathrm{CDCl}_{3}$ as solvent and tetramethylsilane (TMS) as internal standard. Fluorescence photos were taken under a UV lamp, with a Canon 350D digital camera.

\subsection{Synthesis of the dansyl fluorophore and its $\mathrm{Cu}(\mathrm{II})$ metal complex (DNS-Cu)}

The synthesis processes of DNS and the DNS-Cu complex were illustrated in Scheme 1. Firstly, we added 2-chloroethylamine hydrochloride $(65 \mathrm{mg})$ to a dichloromethane $(10 \mathrm{~mL})$ solution of dansyl chloride $(150 \mathrm{mg})$ and triethylamine $\left(\mathrm{Et}_{3} \mathrm{~N} ; 117 \mu \mathrm{L}\right)$. After stirring for $1 \mathrm{~h}$, a pale-yellow oil was obtained by removing the solvent, and then purified via column chromatography with a PE : EA ratio of $4: 1$. The resulting product is herein denoted as compound 1 (107 mg, 61\%). For the synthesis of DNS, we added $62.5 \mathrm{mg}$ of compound 1, $37.6 \mathrm{mg}$ of compound 2, and $27.6 \mathrm{mg}$ of anhydrous $\mathrm{K}_{2} \mathrm{CO}_{3}$ into $3 \mathrm{~mL}$ of a dimethylformamide (DMF) solution. After stirring the mixture for $24 \mathrm{~h}, 15 \mathrm{~mL}$ of ice water was poured into the mixture to generate a precipitate. The

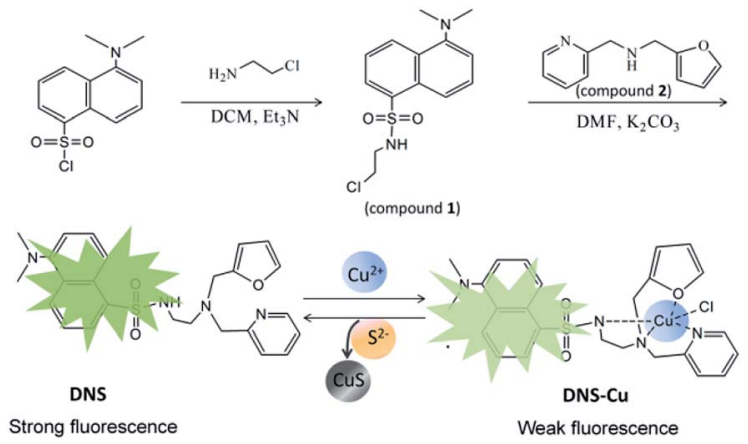

Scheme 1 The scheme shows the synthetic procedure of DNS and its copper complex (DNS-Cu) probe. The DNS-Cu complex probe can combine with $\mathrm{S}^{2-}$ to generate a very stable CuS precipitation and release the DNS fluorophore.

solid crude product was collected through filtration, and the desired pale yellow oil DNS product (40 mg, 43.1\%) was obtained by column chromatography using PE : EA ratios from $4: 1$ to $1: 1$. The DNS-Cu probe complex was easily synthesized by mixing equal molar amounts of DNS and $\mathrm{CuCl}_{2} \cdot 2 \mathrm{H}_{2} \mathrm{O}$ solutions in $\mathrm{C}_{2} \mathrm{H}_{5} \mathrm{OH} / \mathrm{H}_{2} \mathrm{O}(1: 1, \mathrm{v} / \mathrm{v})$. The structures of the DNS and DNS-Cu complex were both characterized by mass spectrometry (MS). Electrospray ionization (ESI) MS (ESI-MS) of DNS $(\mathrm{m} / \mathrm{z})$ : calculated for 464.19, found 465.19 $\left(\mathrm{M}+\mathrm{H}^{+}\right)$, as shown in Fig. S1 in the $\mathrm{ESI} \dagger$ and its proton nuclear magnetic resonance $\left({ }^{1} \mathrm{H}\right.$ NMR; Fig. S2, $\left.\uparrow 400 \mathrm{MHz}, \mathrm{CDCl}_{3}\right) .{ }^{1} \mathrm{H}-\mathrm{NMR}\left(400 \mathrm{MHz}, \mathrm{CDCl}_{3}\right.$ ) $\delta 8.56-8.51(\mathrm{~m}, 1 \mathrm{H}), 8.43(\mathrm{~d}, J=8.5 \mathrm{~Hz}, 1 \mathrm{H}), 8.32(\mathrm{~d}, J=8.7 \mathrm{~Hz}$, $1 \mathrm{H}), 7.53(\mathrm{td}, J=7.7,1.8 \mathrm{~Hz}, 1 \mathrm{H}), 7.45-7.39(\mathrm{~m}, 1 \mathrm{H}), 7.36(\mathrm{dd}, J=$ 8.6, 7.6 Hz, 1H), 7.21 (dd, $J=1.8,0.8 \mathrm{~Hz}, 1 \mathrm{H}), 7.13-7.03(\mathrm{~m}, 3 \mathrm{H})$, $6.69(\mathrm{~s}, 1 \mathrm{H}), 6.15(\mathrm{dt}, J=9.9,4.9 \mathrm{~Hz}, 1 \mathrm{H}), 5.94(\mathrm{~d}, J=2.9 \mathrm{~Hz}, 1 \mathrm{H})$, $3.56(\mathrm{~s}, 2 \mathrm{H}), 3.20(\mathrm{~s}, 2 \mathrm{H}), 2.82-2.92(\mathrm{~m}, 2 \mathrm{H}), 2.75(\mathrm{~s}, 6 \mathrm{H})$, $2.53 \mathrm{ppm}(\mathrm{t}, J=4 \mathrm{~Hz}, 2 \mathrm{H})$.

\subsection{Determination of the binding constant of the DNS-Cu complex}

The stability constant $K$ of the DNS-Cu complex was calculated from a Benesi-Hildebrand plot according to the following Benesi-Hildebrand equation. ${ }^{52,53}$

$$
\frac{1}{F-F_{\min }}=\frac{1}{K\left(F_{\max }-F_{\min }\right)\left(\mathrm{Cu}^{2+}\right)}+\frac{1}{F_{\max }-F_{\min }}
$$

Here, $F_{\max }$ is the fluorescence intensity of the free DNS, $F$ is the fluorescence intensity of DNS with $\mathrm{Cu}^{2+}, F_{\min }$ stands for the fluorescence intensity of DNS in the presence of excessive $\mathrm{Cu}^{2+}$

\subsection{Measurement of quantum yields (QYs) of the DNS-Cu complex}

The QY was measured by using fluorescein $\left(\Phi_{\mathrm{s}}=0.95\right.$ in $0.1 \mathrm{M}$ $\mathrm{NaOH})$ as reference and calculated using the following equation.

$$
\Phi_{F_{\text {sample }}}=\Phi_{F_{\text {standard }}} \frac{\mathrm{Abs}_{\text {standard }}}{\mathrm{Abs}_{\text {sample }}} \frac{\sum F_{\text {sample }}}{\sum F_{\text {standard }}} \frac{\eta_{\text {sample }}{ }^{2}}{\eta_{\text {standard }}{ }^{2}}
$$


where $\Phi_{\mathrm{F}}$ stands for the fluorescence quantum yields, Abs and $\sum F$ denote the absorbance and the measured integrated fluorescence intensity at the excitation wavelength, and $\eta$ is the refractive index of the solvent used. The refractive index of $\mathrm{H}_{2} \mathrm{O}$ and $\mathrm{C}_{2} \mathrm{H}_{5} \mathrm{OH} / \mathrm{H}_{2} \mathrm{O}(1: 1, \mathrm{v} / \mathrm{v})$ mixture solvent was 1.33 and 1.35, respectively.

\subsection{Detection sensitivity of the DNS-Cu complex probe for $\mathrm{H}_{2} \mathrm{~S}$}

Firstly, $2.0 \mu \mathrm{L}$ of the DNS-Cu probe solution $(1.0 \mathrm{mM})$ was added to $2.0 \mathrm{~mL}$ of $\mathrm{a}_{2} \mathrm{H}_{5} \mathrm{OH} / \mathrm{H}_{2} \mathrm{O}(1: 1, \mathrm{v} / \mathrm{v})$ solution, yielding a $1.0 \mu \mathrm{M}$ DNS-Cu concentration in the probe solution. The $\mathrm{Na}_{2} \mathrm{~S}$ solution was freshly prepared used as the $\mathrm{H}_{2} \mathrm{~S}$ source in the aqueous solution. The added concentrations of sulfur ion $\left(\mathrm{S}^{2-}\right)$ in the probe solution were $0,0.125,0.250,0.375,0.500,0.625,0.750,0.875$, $1.000,1.125,1.250$, and $1.375 \mu \mathrm{M}$. The fluorescence spectra were obtained between the range of $400 \mathrm{~nm}$ and $700 \mathrm{~nm}$ under an excitation wavelength of $338 \mathrm{~nm}$. The primary fluorescence peak of the DNS-Cu probe obtained at $534 \mathrm{~nm}$ was employed for $\mathrm{S}^{2-}$ sensitivity testing. The fluorescence ratio $F / F_{0}$ of the DNS-Cu probe, where $F_{0}$ is the value of $F$ obtained with no added $\mathrm{S}^{2-}$ ions, was plotted versus the $\mathrm{S}^{2-}$ ions concentration for quantitative analysis. All data were performed three times under equivalent conditions, and the average values are calculated.

\subsection{Detection selectivity of the DNS-Cu complex probe for $\mathrm{H}_{2} \mathrm{~S}$}

The selective responses of the DNS-Cu probe for other related anions and small molecules containing thiol groups were carefully examined using the same testing procedure as was employed for $\mathrm{S}^{2-}$. The stock solutions of these species $(1 \mathrm{mM}$ of $\mathrm{NO}_{3}{ }^{-}, \mathrm{NO}_{2}{ }^{-}, \mathrm{SO}_{4}{ }^{2-}, \mathrm{SO}_{3}{ }^{2-}, \mathrm{SCN}^{-}, \mathrm{S}_{2} \mathrm{O}_{3}{ }^{2-}, \mathrm{F}^{-}, \mathrm{Cl}^{-}, \mathrm{Br}^{-}, \mathrm{I}^{-}$, $\mathrm{PO}_{4}{ }^{3-}$, and $\mathrm{ClO}^{-}$) were prepared in ultrapure water.

To further illustrate the practical application of the proposed probe, anti-interference experiments were conducted by adding $\mathrm{NO}_{3}{ }^{-}, \mathrm{NO}_{2}{ }^{-}, \mathrm{SO}_{4}{ }^{2-}$, or $\mathrm{SO}_{3}{ }^{2-}$ (50 equiv.), and $\mathrm{SCN}^{-}, \mathrm{S}_{2} \mathrm{O}_{3}{ }^{2-}, \mathrm{F}^{-}$, $\mathrm{Cl}^{-}, \mathrm{Br}^{-}, \mathrm{I}^{-}, \mathrm{PO}_{4}{ }^{3-}$, or $\mathrm{ClO}^{-}$(10 equiv.) into the $\mathrm{DNS}-\mathrm{Cu}$ probe $(1.0 \mu \mathrm{M})$ solution. Then, 1 equiv. of $\mathrm{S}^{2-}$ ions $(1.0 \mu \mathrm{M})$ was added into the mixture solution, followed by recording the fluorescence intensity at $534 \mathrm{~nm}$.

The selectivity of the DNS-Cu probe was also examined for $\mathrm{H}_{2} \mathrm{~S}$ and other different common gases. Gaseous $\mathrm{H}_{2} \mathrm{~S}$ was obtained by slowly dropping phosphoric acid on sodium sulfide. Carbon monoxide (CO) gas was achieved from the reaction of formic acid with concentrated sulfuric acid. Carbon dioxide $\left(\mathrm{CO}_{2}\right)$ gas was prepared from the titration reaction between dilute sulfuric acid and sodium bicarbonate. Sulfur dioxide $\left(\mathrm{SO}_{2}\right)$ was got through a quantitative reaction of sodium hydrosulfide and concentrated sulfuric acid. Ammonia $\left(\mathrm{NH}_{3}\right)$ gas was generated through the chemical reaction between $\mathrm{NH}_{4} \mathrm{Cl}$ and $\mathrm{Ca}(\mathrm{OH})_{2}$. Nitric oxide (NO) and nitrogen dioxide $\left(\mathrm{NO}_{2}\right)$ gas were obtained from pure gas. Then, different of these gas samples were injected into the DNS-Cu probe solution using a syringe, recording the fluorescence spectra subsequently and taking the fluorescence photos by a digital camera.

\section{Results and discussion}

\subsection{Characterization of DNS and DNS-Cu}

The structure of the DNS confirmed by the analysis of MS and ${ }^{1} \mathrm{H}-\mathrm{NMR}$ (Fig. S1 and S2 $\dagger$ ). As illustrated in Scheme 1, the DNS fluorophore exhibits a bright fluorescence at $534 \mathrm{~nm}$, after coordinating with $\mathrm{Cu}^{2+}$, DNS-Cu displays a very weak fluorescence (Fig. S3 $\dagger$ ). The MS analysis verified the formation of the DNS-Cu complex. ESI-MS of DNS-Cu $(\mathrm{m} / \mathrm{z})$ : calculated 526.1100 found 526.0400 (Fig. S4 $\dagger$ ). The value of stability constant $(K)$ for the DNS-Cu complex was determined to be $2.7 \times 10^{4}$ based on Benesi-Hildebrand method, as seen in Fig. S5. $\dagger$

\subsection{Stability and sensitivity of the DNS-Cu probe for $\mathrm{H}_{2} \mathrm{~S}$}

We firstly investigated the stability of the DNS-Cu complex probe before the sensitivity experiment. As noted from Fig. S6, $\dagger$ the fluorescence intensity of the probe at $534 \mathrm{~nm}$ exhibits no distinct changes after six consecutive irradiations for $60 \mathrm{~min}$, indicating that the DNS-Cu complex probe is stable against photobleaching. When the probe solution $(1.0 \mu \mathrm{M})$ is exposed to $\mathrm{S}^{2-}$ ions, as seen in Fig. 1A, the fluorescence intensity of the probe greatly increased as the $\mathrm{S}^{2-}$ ions concentration increased from 0 to $1.375 \mu \mathrm{M}$. This can be attributed to the strong binding of $\mathrm{S}^{2-}$ with the $\mathrm{Cu}(\mathrm{II})$ metal center of the DNS-Cu complex to
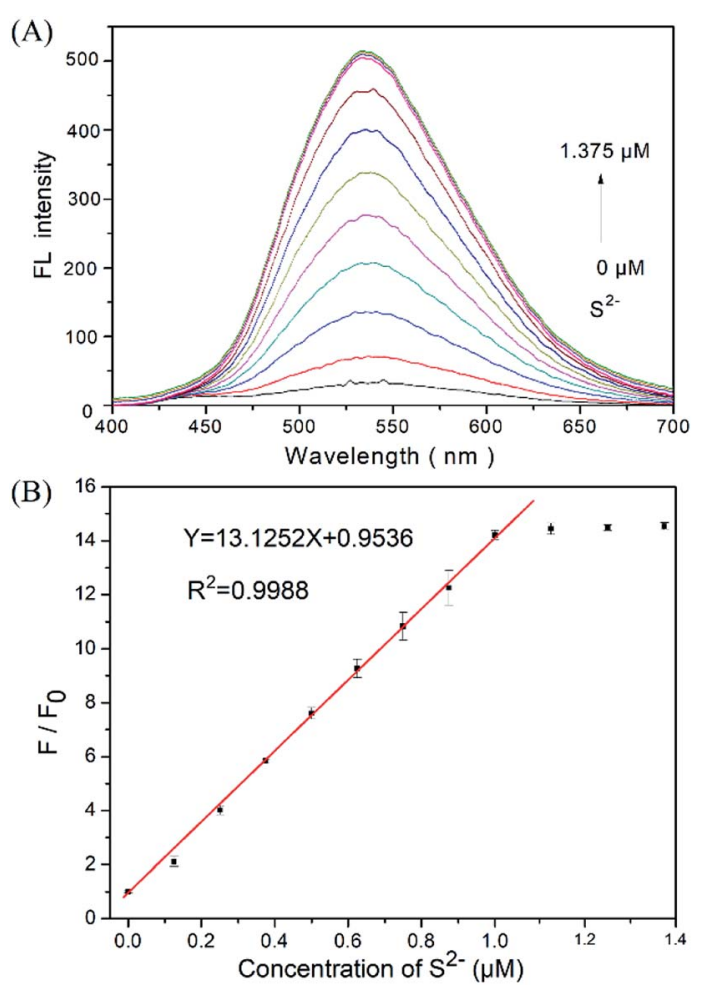

Fig. 1 (A) Fluorescence of the DNS-Cu probe solution $(1.0 \mu \mathrm{M})$ in the presence of different concentrations of $\mathrm{S}^{2-}$ ions. (B) Plot of the fluorescence ratio $F / F_{0}$ of the probe with respect to the $S^{2-}$ concentration, where $F_{0}$ and $F$ represent the fluorescence intensity of the DNS-Cu probe at $534 \mathrm{~nm}$ without and with the addition of $\mathrm{S}^{2-}$ ions, respectively. 
form stable CuS precipitation, subsequently releases the DNS fluorophore. The MS and ${ }^{1} \mathrm{H}$-NMR analysis proved the release of the DNS in Fig. S7, $\uparrow$ and the quantum yields were increased from $1.8 \%$ to $25.5 \%$ after the DNS-Cu probe reaction with $\mathrm{S}^{2-}$ (Fig. $\mathrm{S} 8 \dagger$ ). In addition, the fluorescence intensity exhibits a dose-response with increasing $\mathrm{S}^{2-}$ concentration up to an $\mathrm{S}^{2-}$ dose of $1.0 \mu \mathrm{M}$, after which further increases in the $\mathrm{S}^{2-}$ concentration produce no further increase in the fluorescence intensity. This indicates that the stoichiometric reaction between the DNS-Cu probe and $\mathrm{S}^{2-}$ was $1: 1$. The plot of $F / F_{0}$ versus the $\mathrm{S}^{2-}$ concentration in Fig. 1B exhibits a good linear relationship with a coefficient of determination $R^{2}=0.9988$ in the $\mathrm{S}^{2-}$ concentration range of 0 to $1.0 \mu \mathrm{M}$. The LOD was estimated to be $11 \mathrm{nM}$ based on the definition of $\mathrm{LOD}=3 \times$ S.D. $/ k$, where $k$ is the slope of the curve in Fig. 1B, and $3 \times$ S.D. stands for 3 times standard deviation of the blank signal.

\subsection{Selectivity of the DNS-Cu probe for $\mathrm{H}_{2} \mathrm{~S}$}

As shown in Fig. 2A, the fluorescence intensity of the DNS-Cu probe solution increased sharply after the addition of $\mathrm{S}^{2-}(1.0$ $\mu \mathrm{M})$, whereas no apparent changes in the fluorescence intensity were observed after adding the $\mathrm{NO}_{3}{ }^{-}, \mathrm{NO}_{2}{ }^{-}, \mathrm{SO}_{4}{ }^{2-}, \mathrm{SO}_{3}{ }^{2-}$,
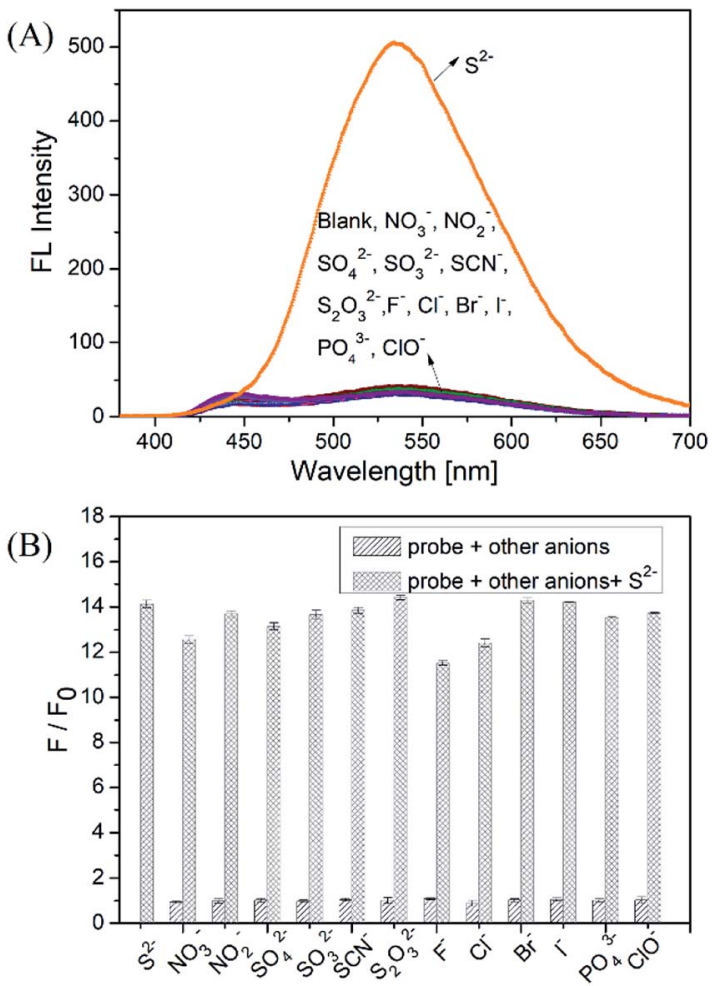

Fig. 2 (A) Fluorescence spectra of the DNS-Cu probe solution (1.0 $\mu \mathrm{M})$ for $\mathrm{S}^{2-}$ ions $(1.0 \mu \mathrm{M})$ and other anion species $(1.0 \mu \mathrm{M})$. (B) $F / F_{0}$ values at $534 \mathrm{~nm}$ of the probe to various anions. The sparse bars represent the fluorescence responses of the probe in the presence of other anions (50 equiv. of $\mathrm{NO}_{3}{ }^{-}, \mathrm{NO}_{2}{ }^{-}, \mathrm{SO}_{4}{ }^{2-}, \mathrm{SO}_{3}{ }^{2-}$ and 10 equiv. of $\mathrm{SCN}^{-}, \mathrm{S}_{2} \mathrm{O}_{3}{ }^{2-}, \mathrm{F}^{-}, \mathrm{Cl}^{-}, \mathrm{Br}^{-}, \mathrm{I}^{-}, \mathrm{PO}_{4}{ }^{3-}$ and $\mathrm{ClO}^{-}$), the dense bars represent the subsequent addition of 1 equiv. of $\mathrm{S}^{2-}(1.0 \mu \mathrm{M})$ into the mixture solution.
$\mathrm{SCN}^{-}, \mathrm{S}_{2} \mathrm{O}_{3}{ }^{2-}, \mathrm{F}^{-}, \mathrm{Cl}^{-}, \mathrm{Br}^{-}, \mathrm{I}^{-}, \mathrm{PO}_{4}{ }^{3-}$, and $\mathrm{ClO}^{-}$anionic species $(1.0 \mu \mathrm{M})$, indicating a high selectivity for $\mathrm{S}^{2-}$ ions. For further practical application, the anti-interference experiments of the probe were conducted by adding $\mathrm{NO}_{3}{ }^{-}, \mathrm{NO}_{2}{ }^{-}, \mathrm{SO}_{4}{ }^{2-}, \mathrm{SO}_{3}{ }^{2-}(50$ equiv.), and $\mathrm{SCN}^{-}, \mathrm{S}_{2} \mathrm{O}_{3}{ }^{2-}, \mathrm{F}^{-}, \mathrm{Cl}^{-}, \mathrm{Br}^{-}, \mathrm{I}^{-}, \mathrm{PO}_{4}{ }^{3-} \mathrm{ClO}^{-}(10$ equiv.) into the probe solution, respectively. Then 1 equiv. of $\mathrm{S}^{2-}$ ions $(1.0 \mu \mathrm{M})$ were added subsequently into the mixture solution, followed by recording the fluorescence intensity at $534 \mathrm{~nm}$. The results of the anti-interference experiments shown in Fig. 2B, indicating that the probe exhibits a good antiinterference against other anionic species.

In order to verify the practicability of probe in complex environments, some biological phosphates (PPi, ATP, ADP, AMP) and endogenous biomolecule (GSH, L-Cys) were investigated with DNS-Cu probe. The results show that the PPi, ATP, ADP and AMP could not turn on the fluorescence of the probe system (Fig. S9†). Even in the presence of 10 equiv. of PPi, ATP, ADP and AMP $(10 \mu \mathrm{M}), \mathrm{H}_{2} \mathrm{~S}(1.0 \mu \mathrm{M})$ also can enhance the fluorescence of the DNS-Cu probe in the same manner as in the absence of these analytes. These results suggest that biological phosphates dose not interference the detection system. However, it is noted that GSH and cysteine could enhance the fluorescence of the DNS-Cu probe, which may be attributed to the affinity of $\mathrm{Cu}^{2+}$ with $-\mathrm{SH}$ groups. Fortunately, their interference with these thiol-containing molecules can be readily eliminated through treatment with dimethyl sulfoxide (DMSO), which oxidizes the thiol groups to form disulfides that have less affinity with $\mathrm{Cu}(\mathrm{II})$, which minimizes their interference effect (Fig. S10†).

\subsection{Potential reusability of the DNS-Cu probe}

The fluorescence of the DNS-Cu probe can be activated by the addition of $\mathrm{S}^{2-}$, quenched by the addition of 1 equiv. of $\mathrm{Cu}(\mathrm{II})$, and then recovered again by adding another 1 equiv. of $\mathrm{S}^{2-}$. As shown in Fig. 3, such fluorescence on-off cycles with $\mathrm{S}^{2-}$ and $\mathrm{Cu}(\mathrm{II})$ could be repeated for 4 times with little degradation in the fluorescence intensity (Fig. 3B), and their corresponding fluorescent images recorded in Fig. 3A. The good reusability of the fluorescent probe for the alternate detection of $\mathrm{S}^{2-}$ and $\mathrm{Cu}^{2+}$ can be developed as a logic gate by operating the two inputs $\operatorname{In}\left(\mathrm{S}^{2-}\right)$ and $\operatorname{In}\left(\mathrm{Cu}^{2+}\right)$, as indicated in Fig. 3C. Optical logic gates, such as the YES, ${ }^{54}$ NOT, ${ }^{55}$ AND, ${ }^{56}$ OR, ${ }^{57}$ NOR, ${ }^{58}$ XOR, ${ }^{59}$ and INHIBIT gates $^{60}$ have been investigated widely in recent years. Here, the two inputs can be set as 0 and 1 to represent the absence and presence of fluorescence, respectively, where exposure to $\mathrm{S}^{2-}$ results in a fluorescence on state, and the output readout is 1 , while the fluorescence would be turned off by exposure to $\mathrm{Cu}^{2+}$ ions, leading to an output of 0 . When there are no inputs of $\mathrm{H}_{2} \mathrm{~S}$ and $\mathrm{Cu}^{2+}$ to the initial logic solution of the probe DNS-Cu complex, it shows no fluorescence, then the output signal is 0 . While both of $\mathrm{H}_{2} \mathrm{~S}$ and $\mathrm{Cu}^{2+}$ exist at the same time, it still no fluorescence, the output signal is 0 as well. Briefly, no fluorescence results from both inputs set as 0 or 1 simultaneously, the output signals were both 0 , which match with the INHIBIT logic function. 

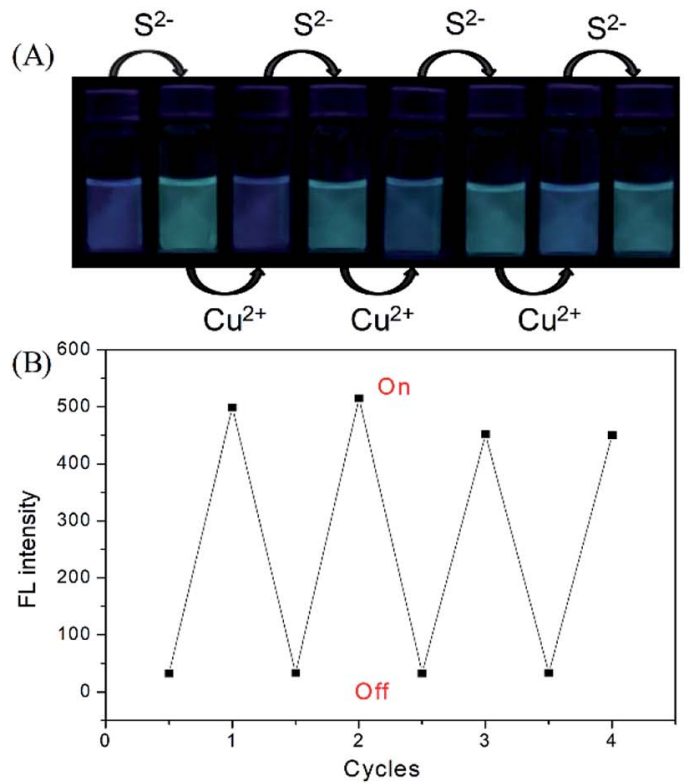

(C)

\begin{tabular}{|cl|c|}
\hline \multicolumn{2}{|c|}{ Inputs } & $\begin{array}{c}\text { Outputs } \\
\operatorname{In}\left(\mathrm{S}^{2-}\right)\end{array}$ \\
\hline $\operatorname{In}\left(\mathrm{Cu}^{2+}\right)$ & 0 (Low Fluorescence) \\
\hline 0 & 0 & 0 (Low Fluorescence) \\
1 & 0 & 1 (High Fluorescence) \\
1 & 1 & 0 (Low Fluorescence) \\
\hline
\end{tabular}

Fig. 3 Fluorescence images (A) and fluorescence intensity (B) of the DNS-Cu probe solution with the alternate addition of $\mathrm{S}^{2-}$ and $\mathrm{Cu}^{2+}$ The photographs were recorded under an ultraviolet (UV) lamp. (C) Logic table of an INHIBIT logic gate.

\subsection{Application of the DNS-Cu probe to actual water samples}

Spike and recovery experiments were conducted using actual lake and mineral water samples. The lake water samples were collected from Shushan lake and filtered through a $0.45 \mu \mathrm{m}$ microporous filter to remove insoluble particles. The mineral water samples were bought from a local supermarket and used directly without any pretreatment. The original concentrations of $\mathrm{S}^{2-}$ in lake water and mineral water samples were firstly confirmed to be $4.2 \mathrm{nM}$ and $5.3 \mathrm{nM}$ by ICPMS (iCAP RQ). These values were much lower than the maximum allowable level of $\mathrm{S}^{2-}(15 \mu \mathrm{M})$ set by World Health Organization (WHO) for drinking water. Thus, they do not pose any health concerns.

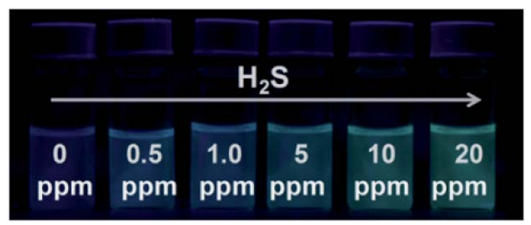

Fig. 4 Visual detection of different concentrations of $\mathrm{H}_{2} \mathrm{~S}$ gas under a UV light illumination in the dark using detector vials.

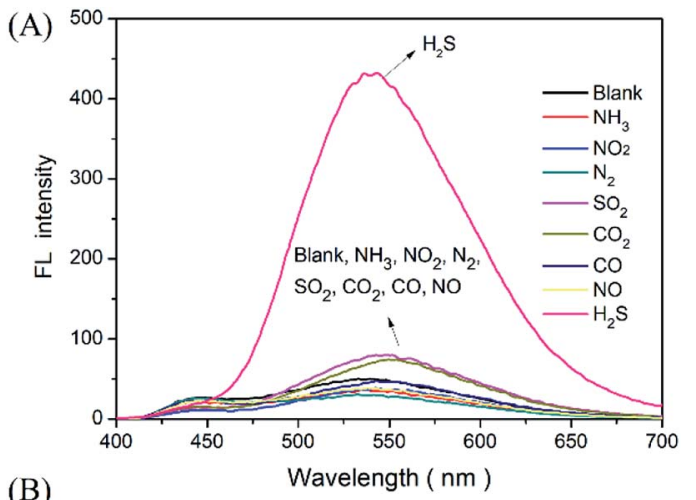

(B)

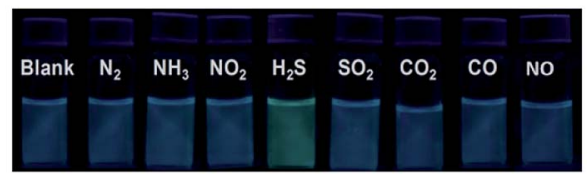

Fig. 5 (A) Fluorescence spectra of the DNS-Cu probe solution for gaseous $\mathrm{H}_{2} \mathrm{~S}$. (B) The fluorescence images of the detector vials taken under a $365 \mathrm{~nm}$ UV lamp. The concentration of $\mathrm{H}_{2} \mathrm{~S}$ gas was $20 \mathrm{ppm}$, $\mathrm{N}_{2}, \mathrm{NH}_{3}, \mathrm{NO}_{2}, \mathrm{SO}_{2}, \mathrm{CO}_{2}, \mathrm{CO}$ and $\mathrm{NO}$ was 100 ppm.

Then the spiked recovery tests were conducted with three different $\mathrm{S}^{2-}$ concentrations $(0,500$, and $1000 \mathrm{nM})$ in a mixed solution of water/ethanol $(\mathrm{v} / \mathrm{v}=1: 1)$. The average concentration and standard deviations of $\mathrm{S}^{2-}$ in the spiked lake and mineral water samples are presented in Table 1 . The concentrations of sulfide estimated in the non-spiked lake and mineral water samples were less than the LOD of the method. The two values are lower than the detection limit, suggesting that the sensitivity of the method has its own limitation and cannot be directly used to real water samples with trace contents, but can be used in the further recovery calculation. The recovery results in the lake water samples are slightly greater than $100 \%$, which may be attributed to the microbial degradation process. Generally, the recovery rates ranged from $98.2 \%$ to $102.3 \%$ for

Table 1 Recovery tests of $\mathrm{S}^{2-}$ ions spiked in lake water and mineral water

\begin{tabular}{lllll}
\hline & Lake water & & Mineral water \\
\cline { 2 - 3 } $\begin{array}{llll}\text { Add S } \\
(\mathrm{nM})\end{array}$ & $\begin{array}{l}\text { Found } \\
(\mathrm{nM})\end{array}$ & $\begin{array}{l}\text { Recovery } \\
(\%)\end{array}$ & \multicolumn{1}{c}{$\begin{array}{l}\text { Found (nM) } \\
(\%)\end{array}$} \\
\hline 0 & 6.2 & & 7.8 & \\
500 & 508 & $101.6 \pm 3.09$ & 491 & $98.2 \pm 1.03$ \\
1000 & 1023 & $102.3 \pm 1.48$ & 997
\end{tabular}


the lake and mineral water samples, which are statistically near $100 \%$, and therefore validates the ability of the proposed probe for $\mathrm{S}^{2-}$ ions sensing in complex samples.

\subsection{Visualization of $\mathrm{H}_{2} \mathrm{~S}$ gas using detector vials}

Since $\mathrm{S}^{2-}$ and $\mathrm{H}_{2} \mathrm{~S}$ can quickly reach equilibrium in aqueous solution, this method can be applied to detect gaseous $\mathrm{H}_{2} \mathrm{~S}$ in aqueous solution. For this measurement, we fabricated detector vials to achieve on-site and rapid detection of gaseous $\mathrm{H}_{2} \mathrm{~S}$. The vials itself has no fluorescence with a rubber stopper, different levels of $\mathrm{H}_{2} \mathrm{~S}$ gas $(0,0.5,1.0,5.0,10$, and $20 \mathrm{ppm})$ were syringed into the vials. The images as presented in Fig. 4 indicate that the fluorescence color intensity in the vials increased with increasing $\mathrm{H}_{2} \mathrm{~S}$ concentration. The limit of detection of this method was determined as $0.5 \mathrm{ppm}$, based on the minimum amount of $\mathrm{H}_{2} \mathrm{~S}$ to produce a slightly different fluorescent color, which could be visible by five persons. The fluorescence intensity of the detector vial achieved a maximum level at an $\mathrm{H}_{2} \mathrm{~S}$ concentration of $20 \mathrm{ppm}$.

In addition, the selectivity of the proposed probe for $\mathrm{H}_{2} \mathrm{~S}$ gas was investigated by evaluating the incidence of fluorescence when filling the detector vials with other common gases, such as $\mathrm{N}_{2}, \mathrm{NH}_{3}, \mathrm{NO}_{2}, \mathrm{SO}_{2}, \mathrm{CO}_{2}, \mathrm{CO}$, and $\mathrm{NO}(100 \mathrm{ppm})$. As presented in Fig. 5. The results indicated that the injection of these other gaseous compounds has no substantial effect on the fluorescence intensity of the probe, and that only $\mathrm{H}_{2} \mathrm{~S}$ gas activated the probe fluorescence. These results demonstrated a sensitivity and selectivity of this method for $\mathrm{H}_{2} \mathrm{~S}$ determination in the gas state.

\section{Conclusions}

We have fabricated a dansyl-based copper complex for use as a "turn-on" fluorescence probe in $\mathrm{H}_{2} \mathrm{~S}$ sensing. The subsequent addition of $\mathrm{H}_{2} \mathrm{~S}$ effectively snatches $\mathrm{Cu}$ (II) from the DNS-Cu complex, and thus releases a free dansyl moiety, leading to the fluorescence enhancement of the probe. The LOD for this method was determined to be $11 \mathrm{nM}$ in aqueous solutions. In addition, the probe provided good $\mathrm{H}_{2} \mathrm{~S}$ detection results with actual water samples. Moreover, the good reusability of the fluorescent probe for cyclical detection of $\mathrm{H}_{2} \mathrm{~S}$ and $\mathrm{Cu}$ (II), which can be used to develop "INHIBIT" logic circuit.

\section{Conflicts of interest}

There are no conflicts to declare.

\section{Acknowledgements}

Financial aid was supported by the National Natural Science Foundation of China (Grant No. 21804100), the National Key Research and Development Program of China (2017YFA0207000), the Natural Science Foundation of Anhui (KJ2018A0416, 1808085QB44), and the Science Foundation of West Anhui University (No. WXZR201801, WGKQ201702020, WGKQ201702002).

\section{References}

1 Y. H. Yan, K. Zhang, H. Yu, H. J. Zhu, M. T. Sun, T. Hayat, A. Alsaedi and S. H. Wang, Talanta, 2017, 174, 387-393.

2 L. Li, M. Bhatia, Y. Z. Zhu, Y. C. Zhu, R. D. Ramnath, Z. J. Wang, F. B. Anuar, M. Whiteman, M. Salto-Tellez and P. K. Moore, FASEB J., 2005, 19, 1196-1198.

3 K. Abe and H. Kimura, J. Neurosci., 1996, 16, 1066-1071.

4 E. Culotta and D. E. Koshland, Science, 1992, 258, 1862-1865.

5 T. Morita, M. A. Perrella, M. E. Lee and S. Kourembanas, Proc. Natl. Acad. Sci. U.S.A., 1995, 92, 1475-1479.

6 C. Y. Miao and Z. Y. Li, Br. J. Pharmacol., 2012, 165, 643-658.

7 G. D. Yang, L. Y. Wu, B. Jiang, W. Yang, J. S. Qi, K. Cao, Q. H. Meng, A. K. Mustafa, W. T. Mu, S. M. Zhang, S. H. Snyder and R. Wang, Science, 2008, 322, 587-590.

8 D. Boehning and S. H. Snyder, Annu. Rev. Neurosci., 2003, 26, 105-131.

9 H. Kimura, Mol. Neurobiol., 2002, 26, 13-19.

10 A. Martelli, L. Testai, M. C. Breschi, C. Blandizzi, A. Virdis, S. Teddei and V. Calderone, Med. Res. Rev., 2012, 32, 10931130.

11 P. Kamoun, M. C. Belardinelli, A. Chabli, K. Lallouchi and B. C. Vekemans, Am. J. Med. Genet., Part A, 2003, 116, 310311.

12 L. L. Yang, J. P. Wang, L. Yang, C. Zhang, R. L. Zhang, Z. Z. Zhang, B. H. Liu and C. L. Jiang, $R S C A d v$., 2016, 6, 56384-56391.

13 K. Eto, T. Asada, K. Arima, T. Makifuchi and H. Kimura, Biochem. Biophys. Res. Commun., 2002, 293, 1485-1488.

14 M. Wronski, Anal. Chem., 1971, 43, 606-607.

15 S. Balasubramanian and V. Pugalenthi, Water Res., 2000, 34, 4201-4206.

16 M. G. Choi, S. Cha, H. Lee, H. L. Jeon and S. K. Chang, Chem. Commun., 2009, 47, 7390-7392.

17 B. Spilker, J. Randhahn, H. Grabow, H. Beikirch and P. Jeroschewski, J. Electroanal. Chem., 2008, 612, 121-130.

18 P. R. Bérubé, P. D. Parkinson and E. R. Hall, J. Chromatogr. A, 1999, 830, 485-489.

19 M. Colon, M. Iglesias, M. Hidalgo and J. L. Todoli, J. Anal. At. Spectrom., 2008, 23, 416-418.

20 D. Y. Gong, X. T. Zhu, Y. J. Tian, S. C. Han, M. Deng, A. Iqbal, W. S. Liu, W. W. Qin and H. C. Guo, Anal. Chem., 2017, 89, 1801-1807.

21 H. H. Li, H. Yu, M. T. Sun, K. A. Alamry, A. M. Asiri and S. H. Wang, Int. J. Environ. Sci. Technol., 2018, 15, 1193-1200.

22 M. T. Sun, H. Yu, H. H. Li, H. D. Xu, D. J. Huang and S. H. Wang, Inorg. Chem., 2015, 54, 3766-3772.

23 J. L. Yao, K. Zhang, H. J. Zhu, F. Ma, M. T. Sun, H. Yu, J. Sun and S. H. Wang, Anal. Chem., 2013, 85, 6461-6468.

24 M. Yang, M. T. Sun, Z. P. Zhang and S. H. Wang, Talanta, 2013, 105, 34-39.

25 F. L. Meng, Z. Guo and X. J. Huang, TrAC, Trends Anal. Chem., 2015, 68, 37-47.

26 F. L. Meng, H. X. Zheng, Y. F. Sun, M. Q. Li and J. H. Liu, Sensors, 2017, 7, 1478. 
27 X. G. San, G. D. Zhao, G. S. Wang, Y. B. Shen, D. Meng, Y. J. Zhang and F. L. Meng, RSC Adv., 2017, 7, 3540-3549.

28 H. J. Peng, Y. F. Cheng, C. F. Dai, A. L. King, B. L. Predmore, D. J. Lefer and B. H. Wang, Angew. Chem., Int. Ed., 2011, 50, 9672-9675.

29 A. R. Lippert, E. J. New and C. J. Chang, J. Am. Chem. Soc., 2011, 133, 10078-10080.

30 B. F. Chen, W. Li, C. Lv, M. M. Zhao, H. Jin, H. F. Jin, J. B. Du, L. R. Zhang and X. J. Tan, Analyst, 2013, 138, 946-951.

31 K. Zhang, J. Zhang, Z. Xi, L. Y. Li, X. X. Gu, Q. Z. Zhang and L. Yi, Chem. Sci., 2017, 8, 2776-2781.

32 Y. H. Yan, H. Yu, Y. J. Zhang, K. Zhang, H. J. Zhu, T. Yu, H. Jiang and S. H. Wang, ACS Appl. Mater. Interfaces, 2015, 7, 3547-3553.

33 Y. Qian, J. Karpus, O. Kabil, S. Y. Zhang, H. L. Zhu, R. Banerjee, J. Zhao and C. He, Nat. Commun., 2011, 2, 495.

34 H. Li, Q. Yao, J. Fan, N. Jiang, J. Wang, J. Xia and X. Peng, Chem. Commun., 2015, 51, 16225-16228.

35 S. Singha, D. Kim, H. Moon, T. Wang, K. H. Kim, Y. H. Shin, J. Jung, E. Seo, S. J. Lee and K. H. Ahn, Anal. Chem., 2014, 87, 1188-1195.

36 C. Zhang, L. Wei, C. Wei, J. Zhang, R. Wang, Z. Xi and L. Yi, Chem. Commun., 2015, 51, 7505-7508.

37 Y. L. Pak, J. Li, K. C. Ko, G. Kim, J. Y. Lee and J. Yoon, Anal. Chem., 2016, 88, 5476-5481.

38 Y. Zhang, H. Chen, D. Chen, D. Wu, X. Chen, S. H. Liu and J. Yin, Org. Biomol. Chem., 2015, 13, 9760-9766.

39 K. Sasakura, K. Hanaoka, N. Shibuya, Y. Mikami, Y. Kimura, T. Komatsu, T. Ueno, T. Terai, H. Kimura and T. Nagano, J. Am. Chem. Soc., 2011, 133, 18003-18005.

40 F. P. Hou, L. Huang, P. X. Xi, J. Cheng, X. F. Zhao, G. Q. Xie, Y. J. Shi, F. J. Cheng, X. J. Yao, D. C. Bai and Z. Z. Zeng, Inorg. Chem., 2012, 51, 2454-2460.

41 X. Li, Y. Gong, K. Wu, S. H. Liang, J. Cao, B. Yang, Y. Hu and Y. Han, RSC Adv., 2014, 4, 36106-36109.

42 J. Y. Kim, S. Sarkar, K. N. Bobba, P. T. Huynh, A. Bhise and J. Yoo, Org. Biomol. Chem., 2019, DOI: 10.1039/c9ob00948e.
43 R. Kaushik, R. Sakla, A. Ghosh, G. T. Selvan, P. M. Selvakumar and D. A. Jose, ACS Sens., 2018, 3, 11421148.

44 R. Kaushik, A. Ghosh and D. A. Jose, Coord. Chem. Rev., 2017, 347, 141-157.

45 S. Wang, H. C. Ding, Y. S. Wang, C. B. Fan, Y. Y. Tu, G. Liu and S. Z. Pu, RSC Adv., 2018, 8, 33121-33128.

46 M. G. Choi, S. Cha, H. Lee, H. L. Jeon and S. K. Chang, Chem. Commun., 2009, 47, 7390-7392.

47 X. Gu, C. Liu, Y. C. Zhu and Y. Z. Zhu, Tetrahedron Lett., 2011, 52, 5000-5003.

48 F. Hou, L. Huang, P. Xi, J. Cheng, X. Zhao, G. Xie, Y. Shi, F. Cheng, X. Yao, D. Bai and Z. Zeng, Inorg. Chem., 2012, 51, 2454-2460.

49 S. Mirra, S. Milione, M. Strianese and C. Pellecchia, Eur. J. Inorg. Chem., 2015, 2272-2276.

50 H. Fang, P. C. Huang and F. Y. Wu, Spectrochim. Acta, Part A, 2018, 204, 568-575.

51 X. F. Shanga, X. J. Yueb, Y. M. Chena, C. S. Lia, H. L. Chenc and T. Y. Wang, Inorg. Chem. Commun., 2019, 99, 1-10.

52 H. A. Benesi and J. H. Hildebrand, J. Am. Chem. Soc., 1949, 71, 2703-2707.

53 S. Zhang, T. Yu, M. T. Sun, H. Yu, Z. P. Zhang, S. H. Wang and H. Jiang, Talanta, 2014, 126, 185-190.

54 Y. Shiraishi, Y. Tokitoh and T. Hirai, Chem. Commun., 2005, 42, 5316-5318.

55 T. B. Pittman, M. J. Fitch, B. C. Jacobs and J. D. Franson, Phys. Rev. A, 2003, 68, 032316.

56 S. Uchiyama, N. Kawai, A. P. de Silva and K. Iwai, J. Am. Chem. Soc., 2004, 126, 3032-3033.

57 P. Ghosh, P. K. Bharadwaj, S. Mandal and S. Ghosh, J. Am. Chem. Soc., 1996, 118, 1553-1554.

58 X. L. Feng, X. R. Duan, L. B. Liu, F. D. Feng, S. Wang, Y. L. Li and D. B. Zhu, Angew. Chem., Int. Ed., 2009, 48, 5316-5321.

59 A. Credi, V. Balzani, S. J. Langford and J. F. Stoddart, J. Am. Chem. Soc., 1997, 119, 2679-2681.

60 R. K. Pathak, K. Tabbasum, A. Rai, D. Panda and C. P. Rao, Anal. Chem., 2012, 84, 5117-5123. 